DOI: $10.1590 / 1809-6891 v 15 i 45553$

\title{
AZITROMICINA NO TRATAMENTO DA ERLICHIOSE MONOCÍTICA EM CÃES NATURALMENTE INFECTADOS
}

\author{
DANIELA TORRES CANTADORI ${ }^{1}$, ANA LUIZA ROSA OSÓRIO ${ }^{2}$, VERONICA JORGE BABO-TERRA ${ }^{2}$ \\ ${ }^{1}$ Médica Veterinária Mestre, Campo Grande, MS, Brasil - danicantadori@uol.com.br \\ ${ }^{2}$ Professoras Doutoras Universidade Federal de Mato Grosso do Sul, Campo Grande, MS Brasil.
}

\section{RESUMO}

Os objetivos deste trabalho foram avaliar a eficácia do tratamento com azitromicina em cães naturalmente infectados por E. canis e acompanhar a evolução clínicohematológica dos animais. Dez cães, com diagnóstico positivo para E. canis por meio do teste de Elisa Snap 4Dx, foram distribuídos em dois grupos, sem tratamento e tratados com azitromicina, $20 \mathrm{mg} / \mathrm{kg}$, via oral, uma vez ao dia, durante sete dias. Além do exame físico diário foram realizados hemogramas, esfregaços de ponta de orelha para a pesquisa de mórulas e nested PCR antes do tratamento e pós-tratamento. Verificou-se que o tratamento não foi eficiente, uma vez que não desapareceram os sinais clínicos, assim como não houve retorno à normalidade dos valores do hemograma nos cães, assim como ausência de eliminação de E. canis.

Palavras-chave: Azitromicina; Ehrlichia canis; PCR; Cães.

\section{AZITHROMYCIN IN THE TREATMENT OF MONOCYTIC EHRLICHIOSIS IN NATURALLY INFECTED DOGS}

\section{ABSTRACT}

The aims of this study were to evaluate the effectiveness of treatment with azithromycin in dogs naturally infected with E. canis, and to analyse the clinical and hematological changes the animals would show. Ten dogs with positive diagnosis for E. canis through Elisa Snap 4Dx test were distributed into two groups, untreated and treated with azithromycin, $20 \mathrm{mg} / \mathrm{kg}$, orally once a day for seven days. In addition to the physical exam, complete

Keywords: azithromycin; Ehrlichia canis; PCR; Dogs.

\section{INTRODUÇÃO}

A erlichiose monocítica canina é causada pela Ehrlichia canis, bactéria gram-negativa intracelular obrigatória, descrita mundialmente e cuja blood counts $(\mathrm{CBC})$, smears made out from blood of the ear margin in order to detect ehrlichial morulae and nested PCR before treatment and post-treatment were performed. We found that the treatment was not effective, since the clinical signs did not disappear, as well as there was no return to normal values of the $\mathrm{CBC}$ in treated animas, neither the elimination of $\mathrm{E}$. canis from the infected animals.

distribuição geográfica está relacionada à presença de seu vetor, o carrapato Rhipicephalus sanguineus $^{1,2}$.

No Brasil, sabe-se que a E. canis está presente em praticamente todos os Estados, mas os 
dados disponíveis são apenas de estudos de algumas regiões e a comparação dos dados epidemiológicos desses estudos é difícil, pois eles diferem a respeito de populações, áreas geográficas, presença de vetores e testes de diagnóstico usados ${ }^{3}$. A doença afeta cerca de 20-30\% dos cães atendidos em clínicas e hospitais veterinários no $\mathrm{Brasil}^{4}$. O maior número de animais positivos é encontrado nas regiões mais quentes do país, incluindo o Estado de Mato Grosso do $\mathrm{Sul}^{5}$, e estudos recentes indicam que cães de áreas urbanas têm um maior risco potencial de exposição a agentes patogênicos das doenças transmitidas por carrapatos comparados aos das áreas rurais devido a uma maior infestação por carrapatos ${ }^{6}$.

A profilaxia deve se concentrar no controle efetivo dos carrapatos, mas também pode ser feita com o uso prolongado da tetraciclina, pois, apesar de algumas tentativas ${ }^{7}$, não existe uma vacina eficaz e os animais não desenvolvem imunidade protetora ${ }^{8}$.

Várias drogas são indicadas para $\mathrm{o}$ tratamento da erlichiose, com sucesso variável, incluindo doxiciclina, dipropionato de imidocarb, tetraciclina, oxitetraciclina, minociclina, enrofloxacina e cloranfenicol. Podem ser necessárias associações como doxiciclina seguida de rifampicina para eliminação do agente ${ }^{9}$.

Infecções por $E$. canis tornam-se mais resistentes à eliminação por doxiciclina conforme a doença progride. Em um estudo ${ }^{10}$, infecções apareceram mais resistentes quando o tratamento foi iniciado durante a fase aguda (16 dpi) do que quando iniciado durante a fase subclínica (62 dpi). Em um estudo anterior, o regime de 14 dias de tratamento com doxiciclina não eliminou a $E$. canis de $\operatorname{cães}^{10}$, indicando que o regime de 28 dias é necessário ${ }^{11}$. Há evidências de que a $E$. canis pode persistir após o tratamento de doxiciclina de hospedeiros infectados naturalmente ${ }^{1,} 8,{ }^{12}$. Embora a droga de eleição definida pelo consenso de experts para tratamento da erlichiose $^{11}$ seja a doxiciclina, em alguns animais em que não seja possível sua administração, justifica-se a utilização de outras substâncias. A rifampicina, por exemplo foi parcialmente eficaz na eliminação da $E$. canis em infecções experimentais em cães ${ }^{13}$.

A azitromicina é um antibiótico macrolídeo que difere estruturalmente da eritromicina pela presença de um metil-nitrogênio substituído no anel lactose. Essa modificação tem produzido um comportamento farmacocinético distinto, o qual é caracterizado por alto nível tecidual e uma longa eliminação, aproximadamente 90 horas em doses múltiplas acima de cinco administrações ${ }^{14,}{ }^{15}$. A associação de azitromicina e atovaquona tem sido utilizada para o tratamento de babesiose em cães ${ }^{16,17}$ e estudos sugerem também que a azitromicina é segura e eficaz no tratamento para papilomatose canina $^{18}$.

É essencial que um agente antimicrobiano com atividade contra organismos intracelulares tenha habilidade de penetrar nas células ${ }^{19}$. Experimentos in vitro e in vivo mostraram que a azitromicina está concentrada em células fagocíticas ${ }^{20}$, enquanto outros autores ${ }^{21}$ sugeriram que o acúmulo da azitromicina em fagócitos está associado à sua atividade contra microrganismos intracelulares.

A atividade da azitromicina tem sido amplamente avaliada na medicina humana em casos de infecção por riquétsias como Orientia tsutsugamushi ${ }^{22,23}$, e até mesmo no tratamento da infecção por Leishmania major ${ }^{24}$ e da leishmaniose cutânea ${ }^{25}$, além de ser largamente comparada à doxiciclina no tratamento de diversas infecções sexualmente transmissíveis, com bons resultados ${ }^{26}$. $\mathrm{Na}$ medicina veterinária, entretanto, devido à escassez de referências, clínicos de pequenos animais vêm utilizando o medicamento como opção terapêutica em casos de reinfecção por E. canis, ou em situações como animais gestantes e filhotes, devido à melhor aceitação da azitromicina por causar menos efeitos colaterais.

A fácil administração da azitromicina (uma dose diária) e o curto período de tratamento em comparação com à doxiciclina favorecem sua prescrição por parte dos médicos veterinários, por ter melhor aceitação do proprietário em relação ao período de 21 a 28 dias necessário para o tratamento com doxiciclina. Da mesma forma, o custo final do tratamento com azitromicina geralmente é menor do que a terapia com doxiciclina.

Os objetivos deste trabalho foram avaliar a eficácia da azitromicina no tratamento da erlichiose monocítica canina, em cães naturalmente infectados, e acompanhar a evolução clínico-hematológica dos animais tratados em relação ao grupo controle.

\section{MATERIAL E MÉTODOS}

Foram pesquisados 44 cães provenientes do Centro de Controle de Zoonoses (CCZ), município de Campo Grande-MS, os quais foram entregues pelos proprietários ao CCZ ou recolhidos das ruas.

O critério de inclusão adotado foi a escolha dos animais baseada na presença de carrapatos e sorologia positiva para E. canis. O critério de exclusão foi a sorologia positiva para Leishmania sp ou infecção concomitante por hemoparasitos como Babesia canis, Hepatozoon canis e Anaplasma platys.

Primeiramente, foram coletadas amostras de sangue total, por meio da punção venosa para obtenção do soro sanguíneo, em frascos 
siliconizados e sem anticoagulante. Em seguida, os soros foram pesquisados quanto à presença de anticorpos anti-E. canis, pelo teste de Elisa, por meio do kit comercial (Snap 4Dx®, laboratório Idexx), que testa a presença de anticorpos anti-Anaplasma phagocytophilum, Borrelia borgdorferi, Ehrlichia canis e Dirofilaria immitis, seguindo as instruções do fabricante. Dez animais sorologicamente positivos para E. canis foram mantidos no Hospital Veterinário da Universidade Católica Dom BoscoUCDB de Campo Grande-MS, durante o período experimental.

Todos os animais selecionados receberam água e ração comercial seca à vontade e foram submetidos a controle de ectoparasitos com pulverização com talco à base da associação de isopropoxifenil e metilcarbamato (talco Bolfo $® ; 1 \%$ de 2-isopropoxifenil-N-metilcarbamato; laboratório Bayer), que permaneceu em cada animal durante 24 horas. Após serem banhados foi aplicado outro princípio ativo, o fipronil (Frontline Top Spot ${ }^{\circledR}$; fipronil; laboratório Merial Saúde Animal), para melhor eliminação dos carrapatos e prevenção de reinfestação. Para o controle de endoparasitas foi utilizada a associação dos princípios ativos pamoato de pirantel, sulfóxido de albendazole e praziquantel (Rico composto®; pamoato de pirantel, sulfóxido de albendazole e praziquantel; laboratório Ouro Fino).

Os animais sorologicamente positivos para E. canis foram distribuídos em dois grupos: controle $(\mathrm{C}, \mathrm{n}=5)$, não tratados, e tratamento $(\mathrm{T}, \mathrm{n}=5) . \mathrm{O}$ tratamento instituído foi a suspensão de azitromicina (Azitromed®; azitromicina diidratada- $200 \mathrm{mg} / 5 \mathrm{ml}$; laboratório Medquímica) na dose de $20 \mathrm{mg} / \mathrm{kg}$ VO a cada 24 horas, durante 7 dias consecutivos. Nenhum outro antibiótico ou tratamento de suporte foi administrado no grupo $\mathrm{T}$.

Os cães foram acompanhados diariamente durante o período de tratamento e pós-tratamento e os dados foram registrados em fichas clínicas. Registraram-se os sinais vitais, consumo de alimento e todos os sinais clínicos apresentados. Foi considerado dia zero (0), o dia do início do tratamento, e dias dez (10) e quatorze (14) os dias para coleta de amostras de sangue para hemograma, punção de baço para a PCR e esfregaço sanguíneo de ponta de orelha para pesquisa de mórula de Ehrlichia spp. Esses intervalos foram determinados com o objetivo de diminuir a interferência do efeito residual da azitromicina, que é de aproximadamente 90 horas $^{27}$.

Foram colhidas de cada animal amostras de $3 \mathrm{~mL}$ de sangue total, por punção da veia jugular e/ou cefálica com auxílio de seringa de $5 \mathrm{~mL}$ e agulha 25x7 descartáveis, para a realização do hemograma. As amostras foram acondicionadas em frascos siliconizados contendo $0,1 \mathrm{~mL}$ de ácido etilenodiaminotetracético (EDTA), em solução a $10 \%$. No hemograma (28), foram avaliados volume globular, hematimetria, hemoglobinometria, leucometria global e específica, hematoscopia e leucocitoscopia. A contagem de plaquetas foi realizada em câmera de Newbauer utilizando-se como diluente oxalato de amônio a $5 \%$ (28). As lâminas foram analisadas por meio de microscopia óptica, utilizando-se objetiva com aumento de $100 \mathrm{X}$ (Olympus ${ }^{\circledR}$ ).

A pesquisa de mórulas foi realizada em esfregaços de sangue, confeccionados a partir de punção, com agulha fina descartável, na ponta da orelha, corados pelo método de May-GrunwaldGiemsa. As lâminas foram analisadas por meio de microscopia óptica, utilizando-se objetiva com aumento de 100 X (Olympus $\left.{ }^{\circledR}\right)$.

Para a PCR no pré-tratamento (dia zero), utilizaram-se as amostras de sangue previamente colhidas para o hemograma. Para a PCR no póstratamento foram colhidas amostras de sangue de punção de baço, guiada por ultra-som e acondicionadas em frascos siliconizados com EDTA. Para esta coleta, os cães foram anestesiados com tiletamina e zolazepan (Zoletilß; tiletamina e zolazepan; laboratório Virbac), na dose de 0,12 $\mathrm{mg} / \mathrm{kg}$. 


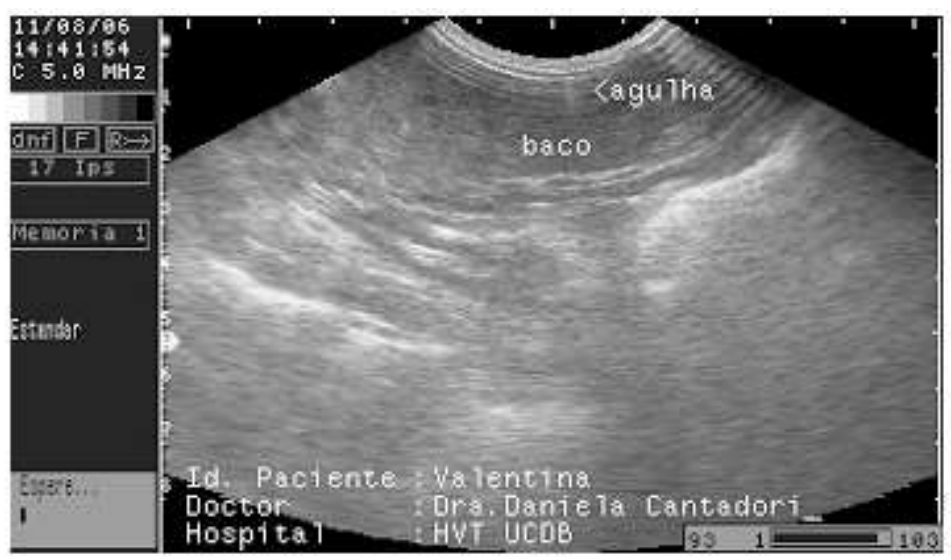

Figura 1. Punção de baço guiada por ultra-som.

A nested PCR foi realizada no Instituto de Biociências do Departamento de Microbiologia e Imunologia da Universidade Estadual Paulista (UNESP), Campus de Botucatu-SP. Foram utilizados $350 \mu \mathrm{L}$ de sangue para extração de DNA por meio do kit comercial (Easy-DNA ${ }^{\mathrm{TM}}$, laboratório Invitrogen Corporation), seguindo-se as orientações do fabricante. Na última etapa da extração, o DNA foi ressuspendido em $100 \mu \mathrm{L}$ de $\mathrm{H}_{2} \mathrm{O}$ ultrapura. A concentração do DNA foi avaliada por eletroforese em gel agarose $0,8 \%$ com marcador lâmbda $(\lambda) 50$ $\mathrm{pb}$ (Laboratório Invitrogen Corporation). Para amplificação de um fragmento do gene $16 \mathrm{~S}$ rRNA de E. canis foi seguida a metodologia de Wen et al. ${ }^{12}$, com as seguintes adequações: foram utilizados $2 \mu \mathrm{L}$ de DNA em reações de $25 \mu \mathrm{L}$, contendo $2,5 \mu \mathrm{L}$ de tampão $10 \mathrm{x} ; 0,8 \mu \mathrm{L}$ de $1,5 \mathrm{mM}$ de $\mathrm{MgCL}_{2} ; 0,5 \mu \mathrm{L}$ $0,25 \mathrm{mM}$ de trifosfato deoxinucleotídeos; $2,5 \mathrm{U}$ de taq polimerase; $100 \mathrm{ng}$ do primer EHO (5'AGAACGAACGCTGGCGGCAAGCC-3'); $100 \mathrm{ng}$ do primer $\quad$ EHO (5'CGTATTACCGCGGCTGCTGGC-3') e $17,7 \mu \mathrm{L}$ de $\mathrm{H}_{2} \mathrm{O}$ ultrapura. A PCR foi realizada a $94{ }^{\circ} \mathrm{C}$ por 1 minuto, $67,5{ }^{\circ} \mathrm{C}$ por 1 minuto e $72{ }^{\circ} \mathrm{C}$ por 1 minuto em termociclador MJ PTC-200.

Para a segunda PCR, foram alteradas apenas as quantidades de DNA $(1 \mu \mathrm{L}), \mathrm{H}_{2} \mathrm{O}$ ultrapura $(18,7 \mu \mathrm{L})$ e os primers utilizados, que foram $100 \mathrm{ng}$ do primer ECA (5'CCATTATTTATAGCCTCTGGCTATAGGAA-3') e 100 ng do primer ECA (5'TATAGGTACCGTCATTATCTTCCCTAT-3'). Um controle positivo com DNA de E. canis e um controle negativo sem DNA foram inclusos em cada PCR. Os produtos da nested PCR foram avaliados em gel da agarose $0,8 \%$, após eletroforese ${ }^{29}$. Os géis foram corados em brometo de etídeo e a massa molecular aparente das bandas protéicas foi determinada conforme mobilidade relativa, com a utilização de software próprio (AlphaDigiDoc ${ }^{\mathrm{TM}}$ Molecular Weigth Calculation - Alpha Innotech Corporation).

As presenças de mórula e positividade na PCR foram avaliadas antes e após o tratamento por meio do teste de Duncan, com nível de significância de $5 \%(\mathrm{p}=0,05)$.

\section{RESULTADOS}

Os resultados de exames clínicos realizados nos dias 0 e 14 estão sumarizados na Tabela 1. Os animais do grupo de tratamento (grupo T) mantiveram-se ativos e comendo, com exceção de um animal, que apresentava muita apatia e escore corporal ruim. Somente um cão, que inicialmente tinha febre, manteve o quadro febril até o dia sete, último dia de administração da azitromicina. Todos os animais deste grupo apresentaram uma significativa melhora no quadro de tosse e secreção nasal e ocular. Somente um animal não apresentava mucosas hipocoradas.

As alterações hematológicas observadas nos exames realizados nos dias 0 e 14 encontram-se na Tabela 2. Os achados mais frequentes nos dois grupos foram anemia e trombocitopenia. No grupo $\mathrm{T}$, todos os animais apresentaram valores de hematimetria no limite inferior de referência $(5,5 \mathrm{a}$ $8,5 \times 10^{3}$ hemácias $/ \mathrm{mm}^{3}$ ) no momento do diagnóstico; no final do experimento, 3 animais apresentaram Tabela 3 - Resultados da pesquisa de mórula e da PCR pré e pós-tratamento mínimo (Tabela 2). No grupo $C$, apenas um animal apresentou redução da hematimetria no início e todos terminaram o experimento anêmicos, sendo que um deles apresentou anemia microcítica e hipocrômica.

Os resultados da pesquisa de mórula, 
visualizada na Figura 2 em esfregaços sanguíneos, e da nested PCR pré-tratamento e pós-tratamento, estão apresentados na Tabela 3.

Tanto os resultados da nested PCR como a presença de mórulas no grupo tratado com azitromicina mostraram que não houve eliminação terapêutica, quando comparados ao grupo controle, já que os dois grupos não diferiram entre si pelo teste de Duncan ( $p>0,05)$ (Tabela 4).

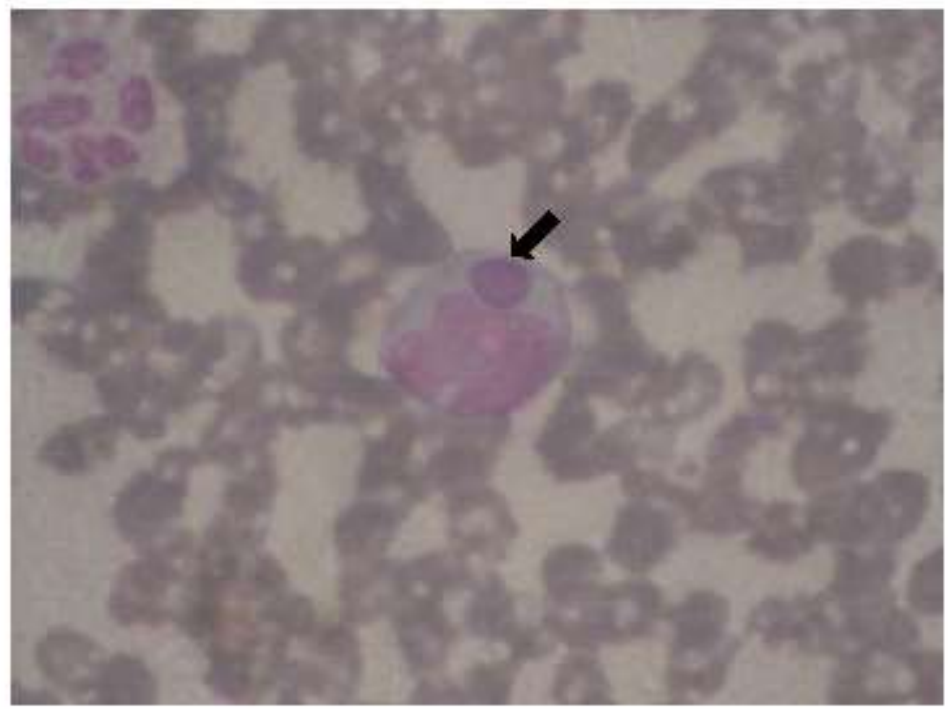

Figura 2. Mórula de E. canis (seta) em monócito apresentando vacuolizações citoplasmáticas (monócito ativado). Aumento de $100 \mathrm{X}$ (Olympus

Tabela 1 - Cães com erlichiose pertencentes ao grupo controle (sem tratamento) e cães tratados com azitromicina, que apresentaram sinais clínicos no dia zero (antes do tratamento) e no dia 14 (pós-tratamento), $\mathrm{n}=5$ em cada grupo

\begin{tabular}{lcccc}
\hline Sinal clínico & \multicolumn{2}{c}{ Grupo Tratamento } & \multicolumn{2}{c}{ Grupo Controle } \\
& Antes & Depois & Antes & Depois \\
\cline { 2 - 5 } Febre $\left(\mathrm{T}^{\mathbf{0}}>\right.$ 39,5) & 1 & 0 & 2 & 2 \\
Emagrecimento & 2 & 1 & 3 & 3 \\
Anorexia & 0 & 1 & 0 & 1 \\
Apatia & 1 & 1 & 1 & 2 \\
Mucosas hipocoradas & 1 & 4 & 2 & 3 \\
Linfadenopatia & 0 & 0 & 2 & 2 \\
Secreção ocular & 4 & 2 & 4 & 3 \\
Tosse & 4 & 2 & 4 & 4 \\
\hline
\end{tabular}

Tabela 2 - $\quad$ Alterações hematológicas em cães observadas no dia zero (0), antes do tratamento; no dia 14, pós-tratamento, nos dois grupos experimentais, $n=5$ em cada grupo

\begin{tabular}{lcccc}
\hline \multirow{2}{*}{ Sinal clínico } & \multicolumn{2}{c}{ Grupo Tratamento } & \multicolumn{2}{c}{ Grupo Controle } \\
& Antes & Depois & Antes & Depois \\
\cline { 2 - 5 } Anemia $\left(<5,5 \times 10^{6} / \mathrm{mm}^{3}\right)$ & 0 & 3 & 1 & 5 \\
Trombocitopenia $\left(<2 \times 10^{4} / \mathrm{mm}^{3}\right)$ & 3 & 2 & 4 & 1 \\
Leucocitose $\left(>17 \times 10^{3} / \mathrm{mm}^{3}\right)$ & 1 & 0 & 0 & 0 \\
Leucopenia $\left(>6 \times 10^{3} / \mathrm{mm}^{3}\right)$ & 2 & 4 & 3 & 1 \\
Neutrofilia $(>11.500)$ & 1 & 0 & 0 & 0 \\
Monocitose $(>1.350)$ & 1 & 0 & 0 & 0 \\
Linfopenia $(<1.000)$ & 4 & 5 & 3 & 3 \\
Presença de Mórula & 5 & 1 & 3 & 2 \\
\hline
\end{tabular}


Tabela 3 - Resultados da pesquisa de mórula e da PCR pré e pós-tratamento

\begin{tabular}{|c|c|c|c|c|c|c|}
\hline \multicolumn{7}{|c|}{ Tratamento } \\
\hline \multirow{2}{*}{ Animal } & \multicolumn{2}{|c|}{ Dia 0} & \multicolumn{2}{|c|}{ Dia 10} & \multicolumn{2}{|c|}{ Dia 14} \\
\hline & mórula & PCR & mórula & PCR & mórula & PCR \\
\hline $\mathrm{T} 1$ & + & + & - & + & - & + \\
\hline $\mathrm{T} 2$ & + & + & - & + & - & - \\
\hline $\mathrm{T} 3$ & + & - & - & + & - & + \\
\hline $\mathrm{T} 4$ & + & + & + & + & - & + \\
\hline \multirow[t]{2}{*}{ T5 } & + & + & + & + & + & + \\
\hline & \multicolumn{4}{|c|}{ Controle } & & \\
\hline \multirow{2}{*}{ Animal } & \multicolumn{2}{|c|}{ Dia 0} & \multicolumn{2}{|c|}{ Dia 10} & \multicolumn{2}{|c|}{ Dia 14} \\
\hline & mórula & PCR & mórula & PCR & mórula & PCR \\
\hline $\mathrm{C} 1$ & + & + & - & + & - & + \\
\hline $\mathrm{C} 2$ & - & - & - & + & - & + \\
\hline $\mathrm{C} 3$ & - & - & + & - & + & + \\
\hline $\mathrm{C} 4$ & + & + & + & + & + & + \\
\hline $\mathrm{C} 5$ & + & + & - & + & - & + \\
\hline
\end{tabular}

Positivo (+) Negativo (-)

Tabela 4 - Médias ordenadas ( \pm erro-padrão) de mórulas e positividade na PCR pré e pós-tratamento

\begin{tabular}{lcccccc}
\hline Grupo & \multicolumn{2}{c}{ Dia $=0$} & \multicolumn{2}{c}{ Dia $=10$} & \multicolumn{2}{c}{ Dia $=14$} \\
& Mórula & PCR & Mórula & PCR & Mórula & PCR \\
\cline { 2 - 7 } Tratamento & $4,5 \pm 1,22^{\mathrm{a}}$ & $5,0 \pm 1,22^{\mathrm{a}}$ & $5,0 \pm 1,22^{\mathrm{a}}$ & $5,0 \pm 1,0^{\mathrm{a}}$ & $6,0 \pm 1,22^{\mathrm{a}}$ & $6,0 \pm 0,0^{\mathrm{a}}$ \\
Controle & $6,5 \pm 0,0^{\mathrm{a}}$ & $6,0 \pm 1,0^{\mathrm{a}}$ & $5,5 \pm 1,22^{\mathrm{a}}$ & $6,0 \pm 0,0^{\mathrm{a}}$ & $5,0 \pm 1,0^{\mathrm{a}}$ & $5,0 \pm 1,0^{\mathrm{a}}$ \\
\hline
\end{tabular}

${ }^{a}$ valores na mesma coluna seguidos pela mesma letra, (a) não diferem entre si pelo Teste de Duncan ( $\left.>>0,05\right)$.

\section{DISCUSSÃO}

Os sinais clínicos (Tabela 1) apresentados pelos cães dos dois grupos foram semelhantes aos descritos na literatura para erlichiose monocítica canina $^{30,31}$. A presença de carrapatos observada no dia 0 (critério de inclusão de todos os animais), a observação de mórulas (tabela 3) (32) e os sinais clínicos observados sugerem que os animais $\mathrm{T} 1, \mathrm{~T} 2$, T3, T4, T5, C1, C4 e C5 estavam na fase aguda da erlichiose. Entretanto, os animais estudados não apresentavam histórico, por serem animais sem proprietários. Além disso, o teste sorológico utilizado detecta apenas contato prévio com o agente etiológico, não sendo possível, desta forma, determinar em que fase da doença os animais se encontravam.

Considerando que esses animais encontravam-se na fase aguda, a resposta ao tratamento não ocorreu conforme esperado ${ }^{33,34}$, isto é, no período de dez dias, intervalo existente entre a primeira e segunda avaliações. O tempo de resposta clínica à terapia sofre interferência da fase da doença ${ }^{1,34}$, sendo mais rápido na fase aguda e mais demorado na fase crônica. Em um estudo ${ }^{7}$, foi utilizada azitromicina na dose de $7 \mathrm{mg} / \mathrm{kg}$, via oral a cada 24 horas por cinco dias, seguido de uma aplicação a cada 72 horas por mais 15 dias em cães na fase aguda da infecção experimental por E. canis como uma alternativa ao uso de tetraciclinas, baseando-se em estudos anteriores que indicaram a eficácia desse medicamento no tratamento de infecções semelhantes como a Febre das Montanhas Rochosas, por exemplo. Os autores observaram falha em amenizar os sinais clínicos e concluíram que a azitromicina não foi eficaz no tratamento da infecção por E. canis.

Na hematologia, a observação de anemia e trombocitopenia, como ocorreu neste estudo são amplamente citadas, em casos de erlichiose ${ }^{30}$. Nos animais sem tratamento, a progressão dessas alterações ocorreu conforme o citado ${ }^{33}$, mas nos animais tratados não houve reversão do quadro ${ }^{11}$. Em estudos que utilizam cães em condições naturais de infecção, como este, torna-se difícil determinar em que fase da doença o animal se encontra ${ }^{31}$ e se ele está completamente livre de outras infecções.

A trombocitopenia demonstrada na primeira avaliação hematológica foi observada por diversos autores e constitui-se na alteração 
hematológica mais consistente que ocorre na erlichiose monocítica canina ${ }^{33}$, geralmente em estágios iniciais da doença ${ }^{35}$, podendo inclusive ser utilizada como triagem para a enfermidade ${ }^{29}$.

neste estudo, dois animais do grupo de tratamento chegaram ao final do experimento sem retorno aos valores de normalidade da contagem de plaquetas. Esses resultados indicam falha no tratamento ${ }^{11}$, pois a plaquetometria pode ser considerada um bom indicador da eficiência da terapia contra $E$. canis, uma vez que a normalização geralmente ocorre dentro de quatorze dias após o tratamento.

A leucocitose é considerada característica na fase aguda da erlichiose ${ }^{33}$. No entanto, ela foi observada em apenas um animal do grupo de tratamento (Tabela 2). A leucopenia geralmente está associada à fase crônica $^{33}$, mas também já foi descrita na fase aguda $^{36}$ e foi observada em cinco animais, sendo dois do grupo tratado e três do grupo controle. Após o tratamento (grupo T), somente um animal terminou o experimento com contagem normal de leucócitos e todos os outros estavam com leucopenia, sendo que um animal apresentava pancitopenia, que é uma alteração relatada na fase crônica por vários autores ${ }^{30}{ }^{33}$. Este animal apresentou mórula em esfregaços sanguíneos durante todo o experimento, sugerindo que se encontrava na fase aguda da doença ${ }^{32}$, demonstrando que as alterações hematológicas não são capazes de determinar em que fase da doença os animais se encontram, em casos de infecção natural, como os do presente estudo.

Entre os animais tratados, somente um animal iniciou o experimento com monocitose, e dois terminaram o tratamento com monocitopenia. Nos animais sem tratamento, todos apresentaram valores normais na contagem de monócitos no final da avaliação. Monocitose é frequentemente descrita na erlichiose ${ }^{30}$, geralmente relacionada à fase aguda $^{33}$. O tempo estimado para normalização dos valores de cada tipo de leucócito durante o tratamento não é abordado de forma específica na literatura, apenas cita-se que há uma melhora ao longo do tratamento ${ }^{37}$.

De acordo com os resultados da PCR prétratamento (Tabela 3), um animal apresentou resultado negativo, embora com mórula em esfregaço sanguíneo. Este mesmo animal apresentou PCR de amostra de baço positiva nos dias 10 e 14 . Isso sugere que a amostra de sangue total não é a melhor escolha para a pesquisa de E. canis por $\mathrm{PCR}^{38}$, de modo que a melhor opção de amostra para PCR pós-tratamento, a fim de avaliar a eliminação da bactéria, seria do baço porque este órgão alberga Ehrlichia por mais tempo. Em nosso estudo, optamos por empregar a nested PCR em amostras de sangue obtidas antes do tratamento devido à aplicabilidade deste método de coleta e sua praticidade na rotina da clínica veterinária de pequenos animais. No pós-tratamento, optou-se pela punção de baço. Contudo, os próprios autores afirmam que a alta sensibilidade da PCR torna as duas formas de amostragem semelhantes ${ }^{38,39}$.

$\mathrm{O}$ animal $\mathrm{T} 2$ apresentou resultado negativo na PCR de amostra de baço no dia 14. Este resultado pode ter ocorrido devido à eliminação da bactéria pelo tratamento ou por ser um animal imunocompetente, que eliminou o microorganismo sem interferência do tratamento ${ }^{33}$. Estudos revelaram que a PCR de punção de baço tornou-se negativa no décimo sexto dia após o início do tratamento com doxiciclina $^{38}$. O resultado negativo no dia 14 , embora em apenas um animal, nos remete à possibilidade da eficácia do tratamento com azitromicina.

$\mathrm{O}$ fato de o animal C3 ter sido negativo na PCR no dia 10 , embora tenha sido positivo na pesquisa de mórula neste mesmo dia (Tabela 3), pode ser devido à presença de coágulo na amostra, pois a rede de fibrina sequestra leucócitos, podendo levar a um resultado falso negativo.

\section{CONCLUSÃO}

A eliminação da $E$. canis em cães naturalmente infectados não foi alcançada pelo tratamento com azitromicina no protocolo utilizado. A terapia com azitromicina não levou à recuperação clínica e ao retorno aos valores de normalidade dos hemogramas dos animais infectados.

\section{REFERÊNCIAS}

1.Harrus S, Waner T, Aizenberg I, Bark H. Therapeutic effect of doxycycline in experimental subclinical canine monocytic ehrlichiosis: evaluation of a 6-week course. Journal of Clinical Microbiology.1998b;36(7):2140-2142.

2. Dantas-Torres, F. The brown dog tick, Rhipicephalus sanguineus (Latreille, 1806) (Acari: Ixodidae): From taxonomy to control. Veterinary Parasitology. 2008; 152 (3-4):173-185.

3. Vieira RF Da C, Biondo AW, Guimarães MAS, Santos AP, Santos RP, Dutra LH, Diniz P PVP, Morais HA, Messick JB, Labruna MB, Vidotto O. Ehrlichiosis in Brazil. Revista Brasileira de Parasitologia Veterinária, Jaboticabal. 2011;20(1):1-12, jan-mar.

4. Trapp SM, Dagnone AS, Vidotto O, Freire RL, Amude AM, Morais HS. Seroepidemiology of canine babesiosis and ehrlichiosis in a hospital population. Vet Parasitol. 2006; 140:223-230.

5. Labarthe N, De Campos Pereira M, Barbarini O, Mckee 
W, Coimbra CA, Hoskins J. Serologic prevalence of Dirofilaria immitis, Ehrlichia canis and Borrelia 6. Vieira TSWJ, Vieira RFC, Nascimento DAG, Tamekuni K, Toledo RS, Chandrashekar R, Marcondes M, Biondo AW, Vidotto O. Serosurvey of tick-borne pathogens in dogs from urban and rural areas from Paraná State, Brazil. Revista Brasileira de Parasitologia Veterinária. 2013; 22(1):104-109.

7. Rudoler N, Baneth G, Eyal O, Van Straten M, Harrus S. Evaluation of an attenuated strain of Ehrlichia canis as a vaccine for canine monocytic ehrlichiosis. Vaccine. 2012; 31: 226-233.

8. Breitschwerdt EB, Hegarty BC, Hancock SI. Doxycycline hyclate treatment of experimental canine ehrlichiosis followed by challenge inoculation with two Ehrlichia canis strains. Antimicrobial Agents and Chemotherapy. 1998; 42(2):362-368

9. McClure JC, Crothers ML, Schaefer JJ, Stanley PD, Needham GR, Ewing SA, Stich RW. Efficacy of a Doxycycline Treatment Regimen Initiated during Three Different Phases of Experimental Ehrlichiosis. Antimicrobial Agents And Chemotherapy, 2010, p. 50125020 .

10. Schaefer JJ, Needham GR, Bremer WG, Rikihisa Y, Ewing SA, Stich RW. Tick acquisition of Ehrlichia canis from dogs treated with doxycycline hyclate. Antimicrobial Agents and Chemotherapy. 2007 (51):3394-3396.

11. Neer TM, Breitschwerdt EB, Greene RT, Lappin MR. Consensus statement on ehrlichial disease of small animals from the infectious disease study group of the ACVIM. Journal of Veterinary Internal Medicine. 2002; 16(3):309-315.

12. Wen B, Rikihisa Y, Mott JM, Greene R, Kim HY, Zhi N, Couto GC, Unver A, Bartsch R. Comparison of nested PCR with Immunofluorescent - antibody Assay for detection of Ehrlichia canis infection in dogs treated with doxycycline. Journal of Clinical Microbiology. 1997;35(7):1852-1855.

13. Theodorou K, Mylonakis ME, Siarkou VI, Leontides L, Koutinas AF, Koutinas CK, Kritsepi-Konstantinou M, Batzias G, Flouraki E, Eyal O,Vassilios K, Harrus S. Efficacy of rifampicin in the treatment of experimental acute canine monocytic ehrlichiosis. Journal Antimicrob Chemother. 2013; 68: $1619-1626$.

14. Girard AE, Girard D, English AR, Gootz TD, Cimochowski CR, Faiella JA, Haskell SL, Retsema JA. Pharmacokinetics and in vivo studies with azithromycin (CP-62.993), a new macrolide with an extended half-life and excellent tissue distribution. Antimicrobial Agents and Chemotherapy. 1987; 31:1948-1954.

15. Zur G, Soback S, Weiss Y, Perry E, Lavy E, Britzi M. Azithromycin pharmacokinetics in the serum and its distribution to the skin in healthy dogs and dogs with pyoderma. The Veterinary Journal. 2014; 200:122-126.

16. Di Cicco MF, Downey ME, Beeler E, Marr H, Cyrog P, Kidd L, Diniz PP, Cohn LA, Birkenheuer AJ. Re- burgdorferi infections in Brazil. Veterinary Therapeutics.2003;4(1):67-75.

emergence of Babesia conradae and effective treatment of infected dogs with atovaquone and azithromycin. Vet Parasitol. 2012 8;187(1-2):23-27.

17. Sakuma M, Setoguchi A, Endo Y. Possible Emergence of Drug-Resistant Variants of Babesia gibsoni in Clinical Cases Treated with Atovaquone and Azithromycin. Journal of Veterinary Internal Medicine. 2009; 23(3): 493498.

18. Yagci BB, Uralt K, Ocal N, Haydardedeoglu AE. Azithromycin therapy of papillomatosis in dog: a prospective, randomized, double-blinded, placebocontrolled clinical trial. Vet Dermatol. 2008; 19:194-198.

19. Schwab JC, Mandell GL. The importance of penetration of antimicrobial agents into cells. Infectious Disease Clinics of North America. 1989;3:461-467.

20. Glaudue RP, Bright GM, Isaacson RE, Newborg MF. In vitro and in vivo uptake of azithromycin (CP-62.993) by phagocytic cells: possible mechanism of delivery and release at sites of infection. Antimicrobial Agents and Chemotherapy. 1989;33:277-282.

21. Wildfewer A, Laufen G, Muller-Wening D, Haferkamp O. Interaction of azithromycin and human phagocytic cells. Uptake of the antibiotic and the effect on the survival of ingested bacteria. Arzneimittel-Forschung. 1989;39:755-758.

22. Watt G, Kantipong P, Jongsakul K, Watcharapichat P, Phulsuksombati D. Azithromycin Activities against Orientia tsutsugamushi Strains Isolated in Cases of Scrub Typhus in Northern Thailand. Antimicrobial Agents and Chemotherapy. 1999; 43(11):2817-2818.

23. Phimda K, Hoontrakul S, Suttinont C, Chareonwat S, Losuwanaluk K, Chueasuwanchai S, Chierakul W, Suwancharoen D, Silpasakorn S, Saisongkorh W, Peacock SJ, Day NPJ, Suputtamongkol Y. Doxycycline versus Azithromycin for treatment of Leptospirosis and Scrub Typhus. Antimicrobial Agents and Chemotherapy. 2007;51(9):3259-3263.

24. Krolewiecki A, Leon S, Scott P, Abraham D. Activity of azithromycin against Leishmania major in vitro and in vivo. American Journal of Tropical Medicine and Hygiene. 2002; 67(3):273-277.

25. Zhou CM, Hu BJ, Gao XD, Bao R, Xie HM, Huang SL, Tao LL, He LX. Antimicrobial susceptibility of community-acquired respiratory tract pathogens isolated from patients in primary hospitals in Shanghai from 2007 to 2010. Zhonghua Jie $\mathrm{He} \mathrm{He} \mathrm{Hu} \mathrm{Xi} \mathrm{Za} \mathrm{Zhi.} \mathrm{2013;}$ 36(5):346-50.

26. Lau CY, Qureshi AK. Azithromycin versus doxycycline for genital chlamydial infections: a metaanalysis of randomized clinical trials. Sexually Transmitted Diseases. 2002; Sep; 29(9):497-502.

27. Pechére JC. The Activity of Azithromycin in Animal Models of Infection. Eur. J. Clin. Microbiol. Dis. 1991; 
10(10):821-827.

28. Kaneko JJ, Harvey JW, Bruss ML. Clinical biochemistry of domestic animals. 5th ed. San Diego: Academic Press. 1997; 932. English.

29. Bulla C, Takahira RK, Araújo Jr JP, Trinca LA, Lopes RS, Wiedmeyer CE. The relationship between the degree of thrombocytopenia and infection with Ehrlichia canis in an endemic area. Veterinary Research. 2004;35(1):141146.

30. Kuehn NF, Gaunt SD. Clinical and hematologic findings in canine ehrlichiosis. Journal of the American Veterinary Medical Association. 1985;186(4):355-358.

31. Moreira SM, Bastos CV, Araújo RB, Santos M, Passos LMF. Estudo retrospectivo (1998 a 2001) da erliquiose canina em Belo Horizonte. Arquivo Brasileiro de Medicina Veterinária Zootecnia. 2003; 55:141-147.

32. Elias E. Diagnosis of ehrlichiosis from the presence of inclusion bodies or morulae of E. canis. Journal of Small Animal Practice. 1991;33(11):540-543.

33. Harrus, S.; Waner, T. Diagnosis of canine monocytotropic ehrlichiosis (Ehrlichia canis): An overview. The Veterinary Journal. 2011; 187: 292-296.

34. Buhles WC, Huxsoll DL, Ristic M. Tropical canine pancytopenia: clinical, hematologic and serologic response of dogs to Ehrlichia canis infection, tetracycline therapy, and challenge inoculation. Journal of Infectious Diseases. 1974;130:357-367.

35. Waner T, Leykin I, Shinitsky M, Sharabani E, Buch H, Keysary A, Bark H, Harrus S. Detection of plateletbound antibodies in beagle dogs after artificial infection with Ehrlichia canis. Veterinary Immunology Immunopathology. 2000;77:145-150.

36. Castro MB, Machado RZ, Aquino LPCT, Alessi AC, Costa MT. Experimental acute canine monocytic ehrlichiosis: clinicopathological and immunological findings. Veterinary Parasitology. 2004;119:73-86.

37. Sousa MG, Higa AC, Gerardi DG, Tinucci-Costa M, Machado R. Tratamento da erlichiose canina de ocorrência natural com doxiciclina, precedida ou não pelo dipropionato de imidocarb. Revista de Ciências Agroveterinárias. 2004; 3:126-130.

38. Harrus S, Kenny M, Miara L, Aizenberg I, Waner T, Shaw S. Comparison of simultaneous splenic sample PCR with blood sample PCR for diagnosis and treatment of experimental Ehrlichia canis infection. Antimicrobial Agents Chemother. 2004; 48: 4488-4490.

39. Faria JLM, Dagnone AS, Munhoz TD, João CF, Pereira WAB, Machado RZ, Tinucci-Costa M. Ehrlichia canis morulae and DNA detection in whole blood and spleen aspiration samples. Revista Brasileira de Parasitologia Veterinária. 2010; 19(2): 98-102. 